\title{
Do tumor and ventricular volume predict the need for postresection shunting in colloid cyst patients?
}

\author{
Kristin J. Weaver, MD, PhD, ${ }^{1}$ Matthew McCord, BS, ${ }^{1}$ Dan Neal, MS, ${ }^{1}$ Frank Bova, PhD, \\ Didier Rajon, PhD, Alfredo Quinones-Hinojosa, MD, ${ }^{2}$ and Maryam Rahman, MD'

\begin{abstract}
'Department of Neurosurgery, University of Florida, Gainesville, Florida; and 2Department of Neurosurgery, Johns Hopkins University, Baltimore, Maryland
\end{abstract}

\begin{abstract}
OBJECTIVE Many colloid cyst patients present with obstructive hydrocephalus that resolves after resection of the cyst. However, a proportion of patients with these cysts will require cerebrospinal fluid shunting after tumor resection, despite resolution of the obstruction at the foramina of Monro. The goal of this study was to determine if colloid cyst size or preoperative ventricular volume predicted the need for postresection shunting.
\end{abstract}

METHODS In a retrospective study design, ICD-9 codes 742.2 (colloid cyst) and 348.0 (brain cyst) were used to identify patients who had undergone resection of a colloid cyst at the University of Florida over the last 20 years. Preoperative imaging (CT or MRI) with a stereotactic software program developed at the University of Florida was used to measure volumes of the colloid cyst and the lateral ventricles. The relationships among ventricular volume, colloid cyst volume, and postoperative shunting were analyzed.

RESULTS The number of patients included in the study was 67 , and their mean age was 37.7 years. Forty percent of the patients were female. Overall, $49.2 \%$ of the patients had a transcallosal approach, $35.8 \%$ a transcortical approach, and $14.9 \%$ an endoscope-assisted surgery. Mean preoperative ventricular volume was $76.5 \mathrm{cc}$ in patients who never received a ventriculoperitoneal shunt (VPS) and $98.1 \mathrm{cc}$ in those who were eventually treated with a VPS $(p=0.305)$. Patients with a postoperative VPS had an initial mean colloid cyst volume of $1.8 \mathrm{cc}$ compared with $0.9 \mathrm{cc}$ in patients without a VPS postoperatively $(p=0.019)$. Patients with colloid cysts larger than $0.6 \mathrm{cc}(1-\mathrm{cm}$ diameter) had a 12.8 increased odds of needing a VPS postoperatively $(95 \% \mathrm{Cl} 1.81-275)$.

CONCLUSIONS Larger colloid cysts are associated with an increased need for postresection shunting independent of preoperative ventricular size. Prospective studies of patients with colloid cysts are necessary to further identify risks of permanent hydrocephalus.

http://thejns.org/doi/abs/10.3171/2015.9.JNS151183

KEY WORDS colloid cyst; hydrocephalus; ventriculoperitoneal shunt

$\mathrm{C}$ OLLOID cysts are benign tumors that arise from the roof of the third ventricle and constitute $0.5 \%-1 \%$ of all central nervous system tumors. . $^{1,4,4,6,22,24,30} \mathrm{Al}$ though many of these cysts are found incidentally, they can cause obstruction of cerebrospinal fluid (CSF) flow, hydrocephalus, and sometimes sudden death given their location near the foramen of Monro..$^{1,8,11,31,32}$ Because of the potential for serious consequences, such as hydrocephalus or death, resection and/or placement of a ventriculoperitoneal shunt (VPS) are recommended for large or symptomatic colloid cysts. Various surgical approaches for colloid cyst resection have been described, including transcortical, transcallosal, endoscopic, and stereotactic aspiration. $1,3,5,7,9,10,12,13,16,17,19-21,23,25-28,30$ Much of the literature on colloid cysts is focused on the risks and benefits of the different surgical approaches since many patients will have resolution of the hydrocephalus after resection. However, up to $25 \%$ of patients will require treatment with a VPS. ${ }^{29}$ But few studies have evaluated the risks associated with the need for a VPS in patients with colloid cysts.

ABBREVIATIONS CSF = cerebrospinal fluid; EVD = external ventricular drain; $L O S=$ length of stay; $V P S=$ ventriculoperitoneal shunt.

SUBMITTED May 20, 2015. ACCEPTED September 11, 2015.

INCLUDE WHEN CITING Published online January 29, 2016; DOI: 10.3171/2015.9.JNS151183. 
The VPS rates in colloid cyst patients vary significantly between studies in the literature, and risk factors for the need for permanent CSF diversion are not well described. Increased ventricular size or intraventricular hemorrhage may be associated with an increased need for permanent CSF diversion, although this hypothesis has not been rigorously studied. The objective in the present study was to determine if patient factors such as preoperative ventricular volume or colloid cyst size influenced the likelihood of needing a VPS after colloid cyst resection.

\section{Methods}

Using a retrospective study design with institutional review board approval, we analyzed all consecutive patients treated for colloid cysts at the University of Florida from 1994 to 2014. Utilizing ICD-9 codes 742.2 (colloid cyst) and 348.0 (brain cyst), we identified all patients who had undergone resection of a colloid cyst. A chart review was performed, and the following information was collected: age at surgery, sex, surgical approach, placement of an external ventricular drain (EVD), postoperative shunt placement, complications (meningitis, seizure, memory deficit, language deficit, motor deficit, visual deficit, CSF leak), length of stay (LOS), and discharge destination. Ventricular and cyst volumes were calculated in patients with preoperative imaging available for analysis. Using this preoperative imaging (CT or MRI) with a stereotactic software program developed at the University of Florida, we measured the volume of both the colloid cyst and the lateral ventricles.

\section{Statistics}

We used the $\mathrm{R}$ statistical software package (version 3.0.2, R Foundation for Statistical Computing) to calculate all descriptive statistics and perform all hypothesis tests. For dichotomous outcomes (shunt and postoperative deficit [yes vs no], discharge disposition [home vs rehab]), we used Fisher's exact tests to compare groups on categorical variables and Mann-Whitney tests to compare them on continuous variables. For shunt status, we also used logistic regression to estimate the effect of cyst volume $(\leq 0.06$ vs $>0.06$ ) when controlling for EVD and postoperative complication. For the LOS outcome, we used Spearman
TABLE 1. Demographics for 67 patients with colloid cysts

\begin{tabular}{cl}
\hline Parameter & No. (\%) \\
\hline Mean age in yrs & 37.7 \\
\hline Sex & \\
\hline Female & $27(40.3)$ \\
\hline Male & $40(59.7)$ \\
\hline Approach & \\
\hline Transcallosal & $33(49.2)$ \\
\hline Transcortical & $24(35.8)$ \\
\hline Endoscopic & $10(14.9)$ \\
\hline
\end{tabular}

correlations to evaluate the relationship between LOS and continuous variables, and the Mann-Whitney or KruskalWallis tests to evaluate the relationship between LOS and categorical variables. Finally, we used linear regression, with the natural log of LOS as the outcome, to test whether cyst volume $(\geq 0.06$ vs $<0.06)$ was associated with LOS when controlling for shunt and EVD status.

\section{Results}

\section{Demographics}

Sixty-seven patients underwent resection of a colloid cyst at the University of Florida in the period from 1994 to 2014 and met the study inclusion criteria. Mean patient age was 37.7 years, and $40 \%$ of the patients were female. As regards surgical approach, $49.2 \%$ of patients had a transcallosal approach, $35.8 \%$ a transcortical approach, and $14.9 \%$ an endoscope-assisted surgery (Table 1). Forty patients had available preoperative imaging that allowed for analysis of cyst and lateral ventricular volumes prior to any intervention; Tables 2 and 3 show patient demographics, cyst volume, ventricular volume, approach, EVD placement, complications, LOS, and discharge disposition for these patients. Fifteen patients (37.5\%) underwent placement of a VPS during their treatment course. There was no difference in the age, sex, surgical approach, or discharge disposition among patients who required a postoperative VPS compared with those who did not. Mean ventricular volume in patients with a VPS was $98.1 \mathrm{cc}$ compared with $76.5 \mathrm{cc}$ in patients without a VPS $(\mathrm{p}=0.305$; Fig. 1$)$. Col-

TABLE 2. Surgical approaches and imaging characteristics of 40 patients with preoperative imaging

\begin{tabular}{llccc}
\hline \multicolumn{1}{c}{ Parameter } & Overall & No Shunt & Shunt & $p$ Value \\
\hline No. of patients (\%) & 40 & $25(62.5)$ & $15(37.5)$ & \\
\hline Mean age in yrs (range) & $36.3(12-60)$ & $36.3(13-60)$ & $36.1(12-54)$ & 0.878 \\
\hline Sex (\%) & & & & 0.094 \\
\hline Female & $16(40.0)$ & $7(28)$ & $9(60)$ & \\
\hline Male & $24(60.0)$ & $18(72)$ & $6(40)$ & \\
\hline Cyst vol in cc (range) & $1.2(0.27-5.6)$ & $0.9(0.27-2.6)$ & $1.8(0.29-5.6)$ & 0.019 \\
\hline Ventricular vol in cc (range) & $84.6(4.0-235)$ & $76.5(4.0-216)$ & $98.1(7.4-235)$ & 0.305 \\
\hline Approach (\%) & & & & 0.087 \\
\hline Transcollosal & $19(40.48)$ & $14(56)$ & $5(33.3)$ & \\
\hline Transcortical & $15(37.5)$ & $6(24)$ & $9(60)$ & $1(6.7)$ \\
\hline Endoscopic & $6(15.0)$ & $5(20)$ & & \\
\hline
\end{tabular}


TABLE 3. Patient factors and the likelihood of undergoing placement of a VPS

\begin{tabular}{|c|c|c|c|c|}
\hline Parameter & Overall & No Shunt & Shunt & $p$ Value \\
\hline No. of patients & 40 & $25(62.5)$ & $15(37.5)$ & \\
\hline EVD placement & & & & 0.006 \\
\hline None & $10(25)$ & $10(40)$ & $0(0)$ & \\
\hline Preop & $6(15)$ & $2(8)$ & $4(26.7)$ & \\
\hline Intraop & $23(57.5)$ & $13(52)$ & $10(67)$ & \\
\hline Postop & $1(2.5)$ & $0(0)$ & $1(6.7)$ & \\
\hline Meningitis & & & & 0.351 \\
\hline No & $38(95)$ & $24(96 \%)$ & $14(93.3 \%)$ & \\
\hline Yes & $2(5)$ & $1(4 \%)$ & $1(16.7 \%)$ & \\
\hline CSF leak & & & & 0.015 \\
\hline No & $36(90.0)$ & $25(100)$ & $11(73.3)$ & \\
\hline Yes & $4(10.0)$ & $0(0 \%)$ & $4(26.7)$ & \\
\hline Postop seizure & & & & 0.359 \\
\hline No & $39(97.5)$ & $25(100)$ & $14(93.3)$ & \\
\hline Yes & $1(2.5)$ & $0(0)$ & $1(6.7)$ & \\
\hline New memory deficit & & & & 0.519 \\
\hline No & $38(95.0)$ & $23(92)$ & $15(100)$ & \\
\hline Yes & $2(5.0)$ & $2(8)$ & $0(0)$ & \\
\hline New language deficit & & & & 0.375 \\
\hline No & $39(97.5)$ & $25(100)$ & $14(93.3)$ & \\
\hline Yes & $1(2.5)$ & $0(0)$ & $1(6.7)$ & \\
\hline New motor deficit & & & & 1 \\
\hline No & $38(95.0)$ & $24(96)$ & $14(93.3)$ & \\
\hline Yes & $2(5.0)$ & $1(4)$ & $1(6.7)$ & \\
\hline New visual deficit & & & & NA \\
\hline No & $40(100)$ & $25(100)$ & $15(100)$ & \\
\hline Yes & $0(0)$ & $0(0)$ & $0(0)$ & \\
\hline Other complication & & & & 1 \\
\hline No & $35(87.5)$ & $22(88)$ & $13(87)$ & \\
\hline Yes & $5(12.5)$ & $3(12)$ & $2(13)$ & \\
\hline LOS in days (range) & $9.0(3-49)$ & $6.9(3-18)$ & $15.2(4-49)$ & $<0.0001$ \\
\hline Discharged home & $35(87.2)$ & $23(92)$ & $12(80)$ & 0.354 \\
\hline Discharge to rehab & $5(12.5)$ & $2(8)$ & $3(20)$ & 0.354 \\
\hline Discharge to hospice & $0(0)$ & $0(0)$ & $0(0)$ & NA \\
\hline
\end{tabular}

$\mathrm{NA}=$ not applicable.

loid cyst volume in patients requiring shunting was larger than that in patients who did not require postresection shunting (1.8 vs $0.9 \mathrm{cc}, \mathrm{p}=0.019$; Fig. 2).

\section{Potential Factors Leading to Postresection Shunting}

There was a marked increase in the likelihood of postoperative shunting for cyst volumes larger than $0.6 \mathrm{cc}$ (Fig. 3). Patients with colloid cysts larger than $0.6 \mathrm{cc}$ had a 12.8 increased odds of needing a VPS postoperatively $(95 \% \mathrm{CI}$ $1.81-275, \mathrm{p}=0.031$ ). Multivariate analysis was performed to see what factors predicted the need for a VPS, a longer LOS, the likelihood of a postoperative complication, or discharge disposition. As expected, patients who underwent placement of VPS were more likely to have an EVD during their treatment course and more likely to have a
CSF leak. Placement of a VPS or an EVD or larger cyst volumes predicted a longer LOS $(\mathrm{p}<0.0001)$. Additional multivariate analysis showed that no variables were significant in predicting postoperative deficits or discharge disposition (Table 3 ).

Of the 67 patients in our cohort, 60 patients had postoperative imaging in our system to evaluate for postoperative hemorrhage. Ventriculoperitoneal shunt placement was evaluated in patients with "any hemorrhage" (parenchymal and intraventricular) and with intraventricular hemorrhage only compared with patients without hemorrhage (Table 4). No statistical difference was found in the VPS rate in patients with any hemorrhage versus no hemorrhage. Patients with postoperative intraventricular hemorrhage had a higher VPS rate (60\%) compared with patients with no 

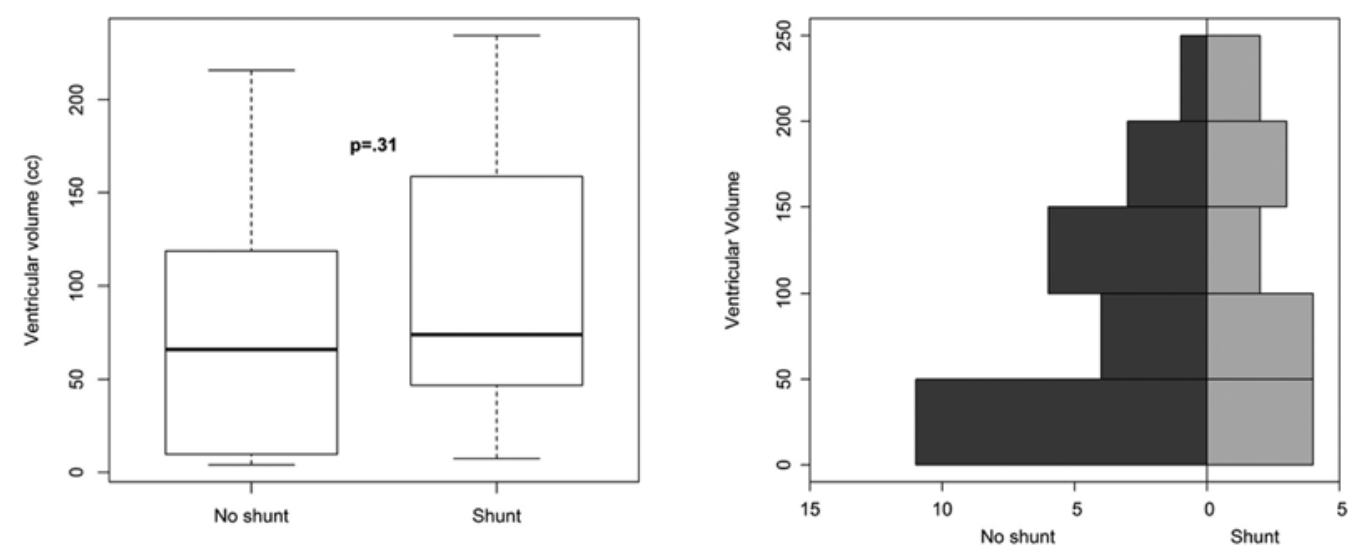

FIG. 1. Ventricular volume by postoperative VPS status. Left: Preoperative ventricular volume is not predicative of the need for postoperative shunt placement. Right: Histograms of ventricular volume versus shunt status.

hemorrhage (40\%), but this difference did not reach statistical significance.

\section{Discussion}

Many colloid cyst patients present with obstructive hydrocephalus that resolves after cyst resection. However, a number of patients will require CSF diversion after colloid cyst resection despite resolution of the obstruction at the foramina of Monro. In this study we found that an increased colloid cyst volume is associated with a greater need for a VPS, independent of the preoperative ventricular size. We also found a trend between postoperative intraventricular hemorrhage and an increased need for a VPS. Although these findings are not surprising, this is the first study demonstrating colloid cyst size and postoperative intraventricular hemorrhage as risks for permanent CSF diversion after colloid cyst resection. Much of the current literature reports VPS rates for colloid cysts without an in-depth analysis of factors associated with VPS placement.

Sheikh et al. performed a large meta-analysis comparing open surgical and endoscopic resection techniques. They included 1278 patients in their study and found a shunt dependency rate of $6.2 \%$ in the microsurgery group and $3.9 \%$ in the endoscopic group $(p=0.12) .{ }^{29}$ In a retrospective study of 134 colloid cyst patients treated with transcallosal resection, $11 \%$ of the patients underwent placement of a VPS preoperatively and $1.5 \%$ underwent VPS insertion after resection. ${ }^{18}$ In another large series of 105 colloid cyst patients, 76 (72.4\%) presented with enlarged ventricles. Overall, 7 patients $(6.7 \%)$ underwent VPS insertion alone and 16 patients $(15.2 \%)$ had placement of a VPS prior to resection. ${ }^{11}$

Hernesniemi et al. published a paper that included a meta-analysis of 1167 cases of colloid cysts in the literature, which described surgical approaches and outcomes. ${ }^{17}$ Some of the surgical approaches included "shunt operation"; however, it was not specified as the sole treatment or placement postresection (3 of 40 patients). Lewis et al. looked at 19 consecutive patients who underwent surgery for colloid cysts. ${ }^{21}$ Seven patients underwent endoscopic resection, whereas 8 patients were treated via a transcallosal approach. One patient was treated with a VPS alone, and 1 patient required a VPS after a transcallosal approach. Hall and Lunsford reported on their 11-year experience with colloid cysts. ${ }^{14}$ These authors had 17 patients, 6 of whom underwent placement of a VPS. Two of the shunts were placed postresection. Morita and Kelly ${ }^{25}$ described postoperative hydrocephalus in 2 (6.7\%) of 30 pa-
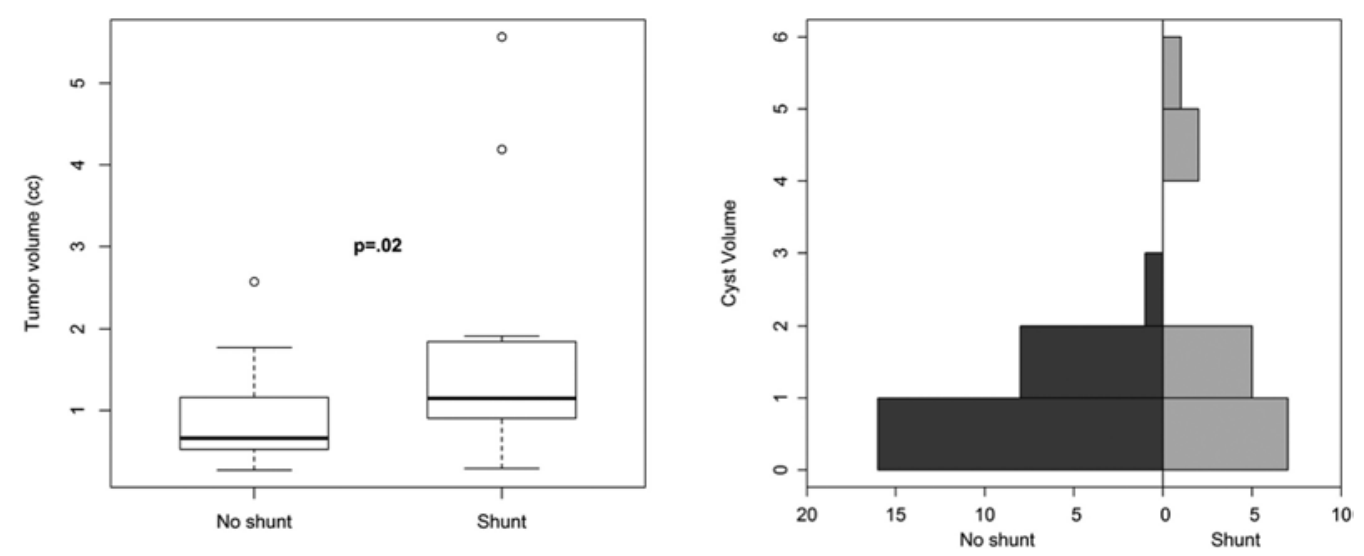

FIG. 2. Cyst volume by postoperative VPS status. Left: Preoperative colloid cyst volume is predictive of the need for postoperative shunt placement. Right: Histograms of colloid cyst volume versus shunt status. 


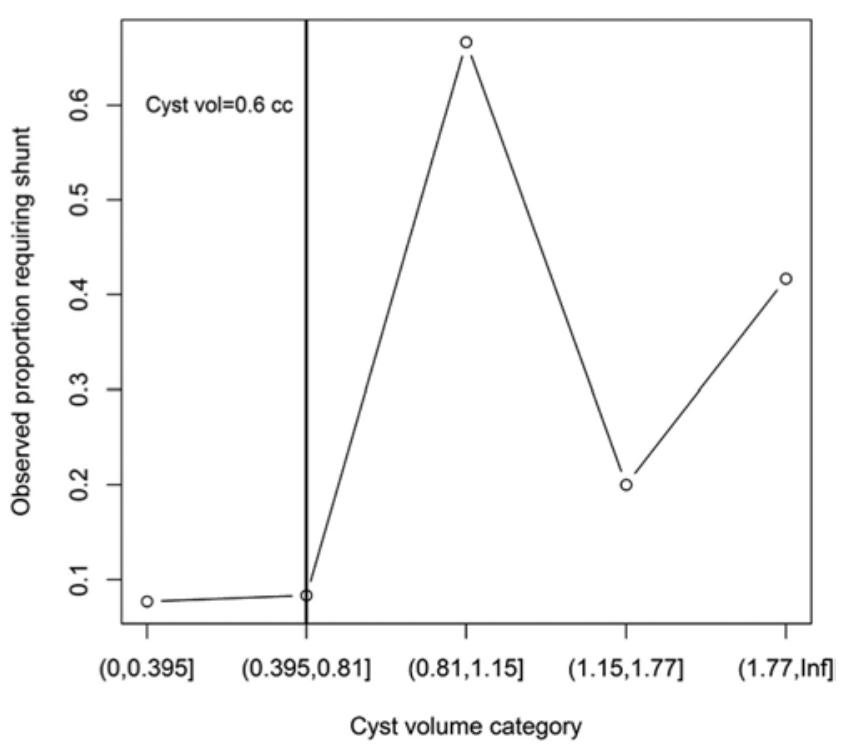

FIG. 3. Probability of requiring a VPS by cyst volume. The data show a marked spike in the likelihood of a shunt for cyst volumes $>0.6 \mathrm{cc}$.

tients treated with transcortical resection. Hellwig et al. ${ }^{15}$ reported on 1 patient (5.6\%), among a series of 18 who had undergone endoscopic resection of a colloid cyst, who required revision of a previously placed shunt.

In the present study, more than $30 \%$ of the colloid cyst patients were treated with a VPS. This high VPS rate is most likely related to multiple factors including surgeon threshold for shunt placement and cyst size in this patient cohort. Larger colloid cysts were associated with an increased likelihood of postresection VPS, independent of preoperative ventricular size. This phenomenon could be related to the CSF fluid dynamics associated with larger cysts but does not appear to be attributable to an increased risk of intraventricular hemorrhage in resecting larger cysts. Moreover, the fact that a larger cyst size is associated with a higher rate of shunting may argue for earlier resection of colloid cysts while they are smaller in size, rather than conservative management. Additionally, the reasons for a higher shunting rate in large colloid cysts can be speculated to include inherent characteristics of the surgery such as longer operative times, more intraoperative bleeding, more irritation of the ventricular surfaces, or more spillage of cyst contents. Unfortunately, given the

TABLE 4. Ventriculoperitoneal shunt status versus postoperative hemorrhage in 60 patients in whom postoperative imaging was available

\begin{tabular}{llll}
\hline \multicolumn{1}{c}{ Parameter } & No Shunt & Shunt & p Value \\
\hline No. of patients & 40 & 20 & \\
\hline Any hemorrhage & & & 0.1739 \\
\hline Yes & $20(50)$ & $14(70.0)$ & \\
\hline No & $20(50)$ & $6(30.0)$ & \\
\hline Intraventricular hemorrhage & & & 0.1102 \\
\hline Yes & $15(37.5)$ & $12(60)$ & \\
\hline No & $25(62.5)$ & $8(40)$ & \\
\hline
\end{tabular}

retrospective design of this study, data points such as those suggested would be limited to the operative reports, which did not necessarily include this type of information.

The limitations of this study include its retrospective design and our reliance on ICD-9 coding in identifying all potential patients with colloid cysts. The retrospective design precludes potentially important factors such as intraoperative bleeding that could impact the need for a VPS. Given the limited number of patients in our cohort, we did not delineate the impact of surgical approach on the need for postoperative shunting.

\section{Conclusions}

Larger colloid cysts are associated with an increased need for postresection independent of preoperative ventricular size. Prospective studies of colloid cyst patients will be necessary to further identify risks of permanent hydrocephalus.

\section{Acknowledgments}

We thank Mu Yang, MS, for assistance with stereotactic volumetric analysis.

\section{References}

1. Abdou MS, Cohen AR: Endoscopic treatment of colloid cysts of the third ventricle. Technical note and review of the literature. J Neurosurg 89:1062-1068, 1998

2. Abernathey CDD, Davis DH, Kelly PJ: Treatment of colloid cysts of the third ventricle by stereotaxic microsurgical laser craniotomy. J Neurosurg 70:525-529, 1989

3. Antunes JL, Louis KM, Ganti SR: Colloid cysts of the third ventricle. Neurosurgery 7:450-455, 1980

4. Apuzzo ML, Chandrasoma PT, Zelman V, Giannotta SL, Weiss MH: Computed tomographic guidance stereotaxis in the management of lesions of the third ventricular region. Neurosurgery 15:502-508, 1984

5. Apuzzo ML, Chikovani OK, Gott PS, Teng EL, Zee CS, Giannotta SL, et al: Transcallosal, interfornicial approaches for lesions affecting the third ventricle: surgical considerations and consequences. Neurosurgery 10:547-554, 1982

6. Campbell JR: Benign intraventricular tumors of the brain. NYSJ Med 40:733-740, 1940

7. Chen TC, Krieger M, Hinton DR, Zee CS, Apuzzo MLJ: The colloid cyst, in Appuzo MLJ (ed): Surgery of the Third Ventricle, ed 2. Baltimore: Williams \& Wilkins, 1998, pp 1071-1132,

8. de Witt Hamer PC, Verstegen MJ, van Furth WR, Bosch DA: Colloid cysts. J Neurosurg 92:906-907, 2000

9. Decq P, Le Guerinel C, Brugières P, Djindjian M, Silva D, Kéravel Y, et al: Endoscopic management of colloid cysts. Neurosurgery 42:1288-1296, 1998

10. Deinsberger W, Böker DK, Bothe HW, Samii M: Stereotactic endoscopic treatment of colloid cysts of the third ventricle. Acta Neurochir (Wien) 131:260-264, 1994

11. Desai KI, Nadkarni TD, Muzumdar DP, Goel AH: Surgical management of colloid cyst of the third ventricle-a study of 105 cases. Surg Neurol 57:295-304, 2002

12. Desai SRS, Sidhu PS, Dawson JM: An usual consequence of stereotactic colloid cyst aspiration. Australas Radiol 41:377-379, 1997

13. Gutierrez-Lara F, Patiño R, Hakim S: Treatment of tumors of the third ventricle: a new and simple technique. Surg Neurol 3:323-325, 1975

14. Hall WA, Lunsford LD: Changing concepts in the treatment 
of colloid cysts. An 11-year experience in the CT era. J Neurosurg 66:186-191, 1987

15. Hellwig D, Bauer BL, Schulte M, Gatscher S, Riegel T, Bertalanffy H: Neuroendoscopic treatment for colloid cysts of the third ventricle: the experience of a decade. Neurosurgery 52:525-533, 2003

16. Hellwig D, Benes L, Bertalanffy H, Bauer BL: Endoscopic stereotaxy-an eight year's experience. Stereotact Funct Neurosurg 68:90-97, 1997

17. Hernesniemi J, Leivo S: Management outcome in third ventricular colloid cysts in a defined population: a series of 40 patients treated mainly by transcallosal microsurgery. Surg Neurol 45:2-14, 1996

18. Hernesniemi J, Romani R, Dashti R, Albayrak BS, Savolainen S, Ramsey C III, et al: Microsurgical treatment of third ventricular colloid cysts by interhemispheric far lateral transcallosal approach-experience of 134 patients. Surg Neurol 69:447-456, 2008

19. Kehler U, Brunori A, Gliemroth J, Nowak G, Delitala A, Chiappetta F, et al: Twenty colloid cysts-comparison of endoscopic and microsurgical management. Minim Invasive Neurosurg 44:121-127, 2001

20. Kelly R: Colloid cysts of the third ventricle; analysis of twenty-nine cases. Brain 74:23-65, 1951

21. Lewis AI, Crone KR, Taha J, van Loveren HR, Yeh HS, Tew JM Jr: Surgical resection of third ventricle colloid cysts. Preliminary results comparing transcallosal microsurgery with endoscopy. J Neurosurg 81:174-178, 1994

22. Little JR, MacCarty CS: Colloid cysts of the third ventricle. J Neurosurg 40:230-235, 1974

23. Mathiesen T, Grane P, Lindgren L, Lindquist C: Third ventricle colloid cysts: a consecutive 12-year series. J Neurosurg 86:5-12, 1997

24. Mathiesen T, Grane P, Lindquist C, von Holst H: High recurrence rate following aspiration of colloid cysts in the third ventricle. J Neurosurg 78:748-752, 1993

25. Morita A, Kelly PJ: Resection of intraventricular tumors via a computer-assisted volumetric stereotactic approach. Neurosurgery 32:920-927, 1993

26. Powell MP, Torrens MJ, Thomson JL, Horgan JG: Isodense colloid cysts of the third ventricle: a diagnostic and therapeutic problem resolved by ventriculoscopy. Neurosurgery 13:234-237, 1983
27. Rivas JJ, Lobato RD: CT-assisted stereotaxic aspiration of colloid cysts of the third ventricle. J Neurosurg 62:238-242, 1985

28. Rodziewicz GS, Smith MV, Hodge CJ Jr: Endoscopic colloid cyst surgery. Neurosurgery 46:655-662, 2000

29. Sheikh AB, Mendelson ZS, Liu JK: Endoscopic versus microsurgical resection of colloid cysts: a systematic review and meta-analysis of 1,278 patients. World Neurosurg 82:11871197, 2014

30. Shucart WA, Stein BM: Transcallosal approach to the anterior ventricular system. Neurosurgery 3:339-343, 1978

31. Stachura K, Libionka W, Moskała M, Krupa M, Polak J: Colloid cysts of the third ventricle. Endoscopic and open microsurgical management. Neurol Neurochir Pol 43:251-257, 2009

32. Wilson DA, Fusco DJ, Wait SD, Nakaji P: Endoscopic resection of colloid cysts: use of a dual instrument technique and an anterolateral approach. World Neurosurg 80:576-583, 2013

\section{Disclosures}

The authors report no conflict of interest concerning the materials or methods used in this study or the findings specified in this paper.

\section{Author Contributions}

Conception and design: Weaver, Bova, Rajon, Quinones-Hinojosa, Rahman. Acquisition of data: Weaver, McCord, Bova, Rajon. Analysis and interpretation of data: Weaver, McCord, Bova,

Rajon. Drafting the article: Weaver. Critically revising the article: Weaver, Quinones-Hinojosa, Rahman. Reviewed submitted version of manuscript: all authors. Approved the final version of the manuscript on behalf of all authors: Weaver. Statistical analysis: Weaver, Neal, Rahman. Study supervision: Rahman.

\section{Correspondence}

Kristin J. Weaver, Department of Neurosurgery, University of Florida, P.O. Box 100265, Gainesville, FL 32610. email: kristin. weaver@neurosurgery.ufl.edu. 